\title{
What Controls the Mean Depth of the PBL?
}

\author{
Brian Medeiros, Alex Hall, and Bjorn Stevens \\ Department of Atmospheric and Oceanic Sciences, University of California, Los Angeles, Los Angeles, California
}

(Manuscript received 2 September 2004, in final form 21 December 2004)

\begin{abstract}
The depth of the planetary boundary layer (PBL) is a climatologically important quantity that has received little attention on regional to global scales. Here a 10-yr climatology of PBL depth from the University of California, Los Angeles (UCLA) atmospheric GCM is analyzed using the PBL mass budget. Based on the dominant physical processes, several PBL regimes are identified. These regimes tend to exhibit large-scale geographic organization. Locally generated buoyancy fluxes and static stability control PBL depth nearly everywhere, though convective mass flux has a large influence at tropical marine locations. Virtually all geographical variability in PBL depth can be linearly related to these quantities. While dry convective boundary layers dominate over land, stratocumulus-topped boundary layers are most common over ocean. This division of regimes leads to a dramatic land-sea contrast in PBL depth. Diurnal effects keep mean PBL depth over land shallow despite large daytime surface fluxes. The contrast arises because the large daily exchange of heat and mass between the PBL and free atmosphere over land is not present over the ocean, where mixing is accomplished by turbulent entrainment. Consistent treatment of remnant air from the deep, daytime PBL is necessary for proper representation of this diurnal behavior over land. Many locations exhibit seasonal shifts in PBL regime related to changes in PBL clouds. These shifts are controlled by seasonal variations in buoyancy flux and static stability.
\end{abstract}

\section{Introduction}

The planetary boundary layer (PBL) is a critical component of earth's climate system. It mediates the exchanges of heat, momentum, moisture, and chemical constituents between the surface and free atmosphere and is the largest sink for atmospheric kinetic energy. Boundary layer processes are also primarily responsible for low clouds like stratocumulus and are of fundamental importance for cumulus convection, implying that the PBL has important roles in both the atmospheric radiative and heat budgets. Because of this crucial role, there is general agreement that large-scale models must include some representation of boundary layer processes to simulate essential climatic quantities like global cloudiness, precipitation, and surface winds.

PBL parameterizations are often based around a few boundary layer regimes. Figure 1 is an idealized schematic depicting a variety of these regimes and the largescale environment thought to be conducive to their formation (see also Lock et al. 2000). On the left-hand side

Corresponding author address: Brain Medeiros, Department of Atmospheric and Ocean Sciences, 405 Hilgard Ave., Box 951565, Los Angeles, CA 90095-1565.

E-mail: brianpm@atmos.ucla.edu are regimes with large surface latent heat and convective mass fluxes, where active cumulus convection covers a few percent of the area. The other cloudy boundary layers occur over cooler sea surfaces and mostly exist under an inversion related to the subsiding branch of the Hadley-Walker circulation, encouraging more homogeneous cloud coverage. Two kinds of clear PBL are shown over land: the stable boundary layer (SBL) and the (dry) convective boundary layer (CBL). SBLs occur most often over cold surfaces or during nighttime over land; CBLs are the dominant PBL regime over land during daytime, when surface fluxes drive convective updrafts. Farthest to the right in the figure is a fair-weather cumulus boundary layer, with a CBL below shallow cumulus.

There are now detailed datasets describing the PBL under various large-scale conditions. Intensive observational campaigns have been undertaken over diverse surface types in many regions. A few of these observations are listed in Table 1. These and similar data have been used in developing large-eddy simulations (LESs) and PBL parameterizations. The local nature of these kinds of observations, however, makes them most useful for understanding particular PBL regimes, not generalized PBL behavior.

Large-scale modeling studies have mostly focused on 


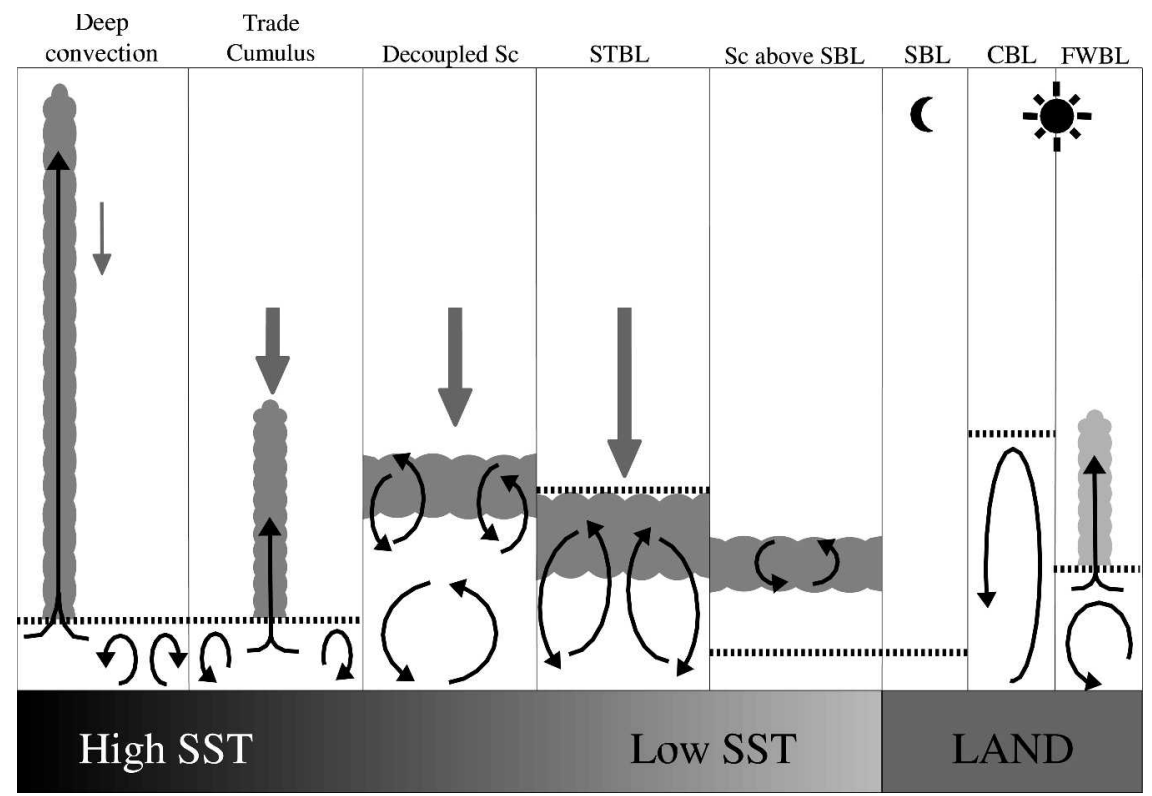

FIG. 1. Schematic view of several PBL regimes. From left to right: deep convection, shallow cumulus $(\mathrm{Cu})$, stratocumulus ( $\mathrm{Sc}$ ) decoupled from the subcloud layer, stratocumulus-topped boundary layer (STBL), stratocumulus overlying a stable boundary layer (SBL), two clear boundary layers (convective and stable), and a fair-weather cumulus boundary layer (FWBL) with a convective subcloud layer and a cumulus cloud layer. The top of the PBL, as defined by the UCLA GCM, is marked by dotted lines, except in the case of the decoupled Sc layer, which is not represented by the model. Dark arrows are representative of the local circulation, with cumulus mass flux removing mass from the PBL in the cumulus regimes and convective cells in the other convective regimes. Stable boundary layers may be turbulent, but not convective, so arrows are neglected. The gray arrows pointed downward represent large-scale subsidence, which tends to increase the static stability.

parameterization validation. These studies sometimes compare observations and large-scale models using single grid points (e.g., Garratt et al. 2002), keeping with the local view of most observations. Comparisons on large scales are rare because few adequate largescale PBL observations exist. As part of testing the parameterization of Lock et al. (2000), Martin et al. (2000) include a qualitative comparison with satellite imagery. Randall et al. (1998) compare two climate models to global observations [Comprehensive OceanAtmosphere Data Set (COADS) surface fluxes, Lidar In-space Technology Experiment (LITE) PBL depth, and International Satellite Cloud Climatology Project (ISCCP) stratus cloud amount], but few conclusions are drawn as the focus is on reviewing PBL parameterizations in climate models. Parameterization evaluations usually show cautious optimism about their relative success, but a true validation must wait for a more complete PBL dataset.

Considering the attention given to treatment of the PBL, there is little sense of the global distribution of PBL depth and its relationship to the large-scale conditions. Until now it has been impossible to observe the large-scale structure of the PBL depth [except the proof-of-concept LITE (McCormick et al. 1993; Winker et al. 1996)]. In coming years though, satellite remote sensing projects [e.g., Atmospheric Infrared Sounder (AIRS); Cloud-Aerosol Lidar and Infrared Pathfinder Satellite Observations (CALIPSO); Clouds and the Earth's Radiant Energy System (CERES); Ice, Cloud, and Land Elevation Satellite (ICESAT)] are expected to produce global datasets for PBL depth and other boundary layer quantities. As these data become available, it is valuable to develop an intuition for the large-scale behavior of the PBL using large-scale models. This will introduce a framework for integrated analysis of observations and simulations in a global context. A global perspective is desirable for exploring the role of the PBL in global climate and may help in developing simplified PBL representations for idealized climate models.

This study utilizes the University of California, Los Angeles (UCLA) atmospheric general circulation model (GCM) to reveal the processes regulating PBL depth on large scales. This GCM is particularly appropriate for such a study because it goes to extraordinary 
TABLE 1. Some field studies with detailed PBL data.

\begin{tabular}{|c|c|c|}
\hline Surface/region & Project & Reference \\
\hline Flat grassland & FIFE $^{\mathrm{a}}$ & Sellers et al. (1992) \\
\hline Boreal forest & BOREAS & Sellers et al. (1995) \\
\hline Amazon basin & $\mathrm{LBA}^{\mathrm{b}}$ & $\begin{array}{l}\text { Avissar and Nobre } \\
\text { (2002) }\end{array}$ \\
\hline \multirow[t]{3}{*}{ Eastern Pacific } & EPIC & Bretherton et al. (2004) \\
\hline & DYCOMS-II & Stevens et al. (2003) \\
\hline & DYCOMS & Lenschow et al. (1988) \\
\hline Western Pacific & TOGA COARE & $\begin{array}{l}\text { Webster and Lukas } \\
\text { (1992) }\end{array}$ \\
\hline $\begin{array}{c}\text { Subtropical } \\
\text { Atlantic }\end{array}$ & ASTEX $^{\mathrm{d}}$ & Albrecht et al. (1995) \\
\hline Ice-covered seas & SHEBA $^{\mathrm{e}}$ & Uttal et al. (2002) \\
\hline
\end{tabular}

${ }^{a}$ First International Satellite Land Surface Climatology Project (ISLSCP) Field Experiment.

${ }^{\mathrm{b}}$ Large Scale Biosphere-Atmosphere Experiment in Amazonia.

${ }^{c}$ Tropical Ocean Global Atmosphere Coupled Ocean-Atmosphere Response Experiment.

d Atlantic Stratocumulus Transition Experiment.

${ }^{\text {e }}$ Surface Heat Budget of the Arctic Ocean.

lengths to consistently couple the budgets of mass, heat, and moisture within the PBL to the processes believed to influence the PBL (e.g., cumulus convection, radiative fluxes). This is accomplished using a mixed-layer framework in which PBL depth is a prognostic variable (see section 2). The climatological PBL depth from a 10-yr simulation (Fig. 2) is analyzed primarily by examining the PBL mass budget. A simple dry CBL model and a second GCM simulation excluding the diurnal cycle are also used. The annual mean is the primary focus, although both the diurnal and seasonal variations are important to the mean depth, and so are also studied.

\section{Models}

This section reviews some aspects of the UCLA atmospheric GCM relevant for this study. A more com-

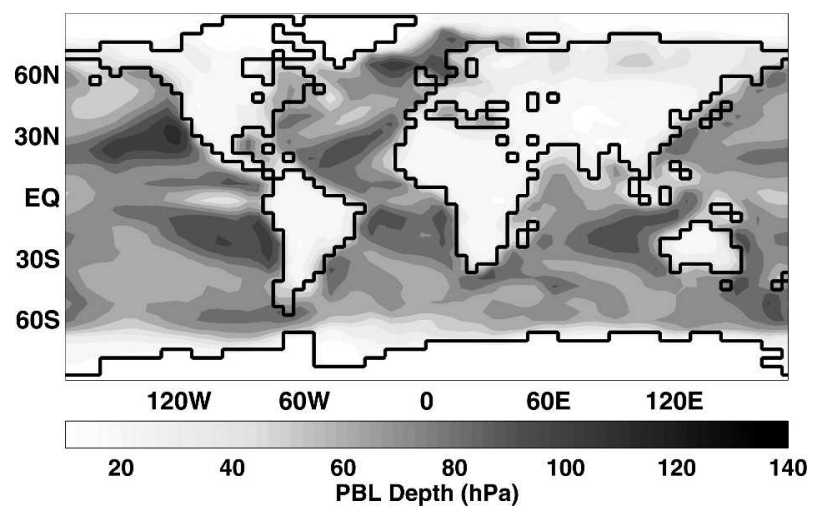

FIG. 2. Annual-mean PBL depth (hPa) from the 10-yr GCM simulation. Contours are every $10 \mathrm{hPa}$, from 10 to $140 \mathrm{hPa}$. plete description is provided by Mechoso et al. (2000) and references therein. This GCM is well suited to studying PBL processes because it makes use of a modified vertical sigma coordinate in which the PBL is synonymous with the lowest model layer. The PBL top acts effectively as a material surface with immediately overlying coordinate surfaces following the PBL's vertical variations and higher levels gradually tending toward uniform pressure surfaces. This configuration was implemented by Suarez et al. (1983), incorporating the mixed-layer theory of Lilly (1968) and the surface flux scheme of Deardorff (1972).

This vertical coordinate system distinguishes the UCLA GCM and its descendants from other models. Most GCMs use eddy diffusion models with fixed vertical levels to represent boundary effects, and the PBL depth is often diagnosed separately from the dynamics. These treatments can introduce inconsistencies by failing to ensure that effective mixing rates between the PBL and free troposphere are the same for mass, heat, and moisture. In some models the diagnosed depth is used in the subsequent dynamic time step, but many models do not use the depth as a dynamical length scale (see review in Moeng and Stevens 2000). In the UCLA GCM, however, the PBL has been integrated so it is consistently coupled to processes in the lower troposphere, making it especially useful for investigating PBL behavior.

Parameterizing stratocumulus clouds is also simplified by this approach. The GCM diagnoses cloud incidence by determining the lifting condensation level (LCL) of mixed-layer air and comparing it to the PBL depth. If the LCL is below the PBL top, stratocumulus are predicted (see Suarez et al. 1983; Li and Arakawa 1999; Li et al. 2002 for details). In later sections it is shown that the presence of stratocumulus profoundly affects mean PBL depth. Bearing that in mind, it is relevant that stratocumulus in this GCM are also affected by cloud-top entrainment instability (CTEI; Randall 1980; Deardorff 1980). CTEI can dissipate stratocumulus by entraining warm, dry air into the PBL, and the assumptions involved may affect the global climatology in several ways, which is considered in the following analysis.

One problem introduced by a single-layer PBL is that sometimes the PBL depth is ambiguous. A prominent example is deep convection, when the entire troposphere becomes effectively well mixed. To avoid numerical problems in such situations, the PBL top is set at cloud base, so the PBL is only the subcloud layer (Fig. 1). As a consequence of this definition, stratocumulus layers tend to appear as regions of deep PBL, 
while regions dominated by cumulus convection usually have a comparatively shallow PBL. This convention also applies to regions of shallow cumulus convection, for example, downstream of stratocumulus decks. The GCM does not explicitly parameterize shallow convection, but relies on the moist convection scheme and CTEI to capture this regime (see Randall et al. 1985). Occasionally this leads to some discrepancy between the GCM and observed climatologies; usually shallow convection appears as a shallow PBL with the top at cloud base.

For numerical stability, upper and lower limits are imposed on the PBL depth. The upper limit is $15 \%$ of the total tropospheric depth. This limit can be circumvented since the second vertical layer is not required to be thermodynamically distinct from the PBL (Suarez et al. 1983). The lower limit $(10 \mathrm{hPa})$ avoids difficulties with horizontal advection in the PBL. Because the model framework is a mixed-layer approach, stable boundary layers are not well represented. However, since a typical SBL depth is around $10 \mathrm{hPa}$ [e.g., Barr and Betts (1997) report 9-13 hPa during BOREAS], it is assumed that the lower limit represents the stable regime of Fig. 1. The lower limit is most often found where surface temperatures are low and/or where there is little solar radiation, conditions that promote gravitational stability, so the assumption seems reasonable.

For this study, a coarse resolution $\left(4^{\circ} \times 5^{\circ}\right)$ grid is used with climatological SST and sea ice concentration. Most of the analysis uses monthly means calculated from hourly snapshots of the simulation. Additionally, 12-times-daily snapshots were saved for one year for examination of the diurnal cycle. The large grid spacing precludes discussion of mesoscale (or smaller) features such as the shoaling of the PBL near coastlines where stratocumulus become thin (Neiburger et al. 1961). Thus the focus is on regional-scale and larger characteristics of PBL depth.

To isolate physical processes determining the climatological PBL depth and its diurnal variation, a model of the dry convective PBL was developed. The model uses prescribed solar forcing and a surface energy budget to calculate PBL depth. The surface warms the boundary layer, which grows by a simple entrainment rule. A slowly cooling residual layer is included above the boundary layer to represent remnant air often found above the nocturnal PBL. The advantage of such a simplified model is its small number of parameters, making interpretation of the results more straightforward than the GCM. This allows dominant processes determining PBL depth to be isolated. The details of this CBL model are found in the appendix.

\section{Mean state of the PBL}

\section{a. Mean PBL depth}

In Fig. 2 the climatological mean PBL depth is generally much shallower over land than ocean. This runs counter to the intuitive notion of a deep PBL over warm land regions. The large diurnal variation in ground temperature is a key factor in this land-sea contrast, as will be shown in the next section.

Also evident in Fig. 2 are regions of deep PBL over eastern ocean basins. A comparison with a map of stratus incidence (not shown) shows qualitative agreement between these regions and high stratus incidence. The Californian and Peruvian stratiform regions have especially deep PBL. The Namibian, Canarian, and Australian stratus are also evident, though less dramatically. Stratocumulus correspond to large PBL depth because convective fluxes raise the PBL top above the LCL without initiating deeper convection. When conditions become more favorable for cumulus, the GCM reduces the PBL top to cloud base (section 2).

At high latitudes, the mean PBL depth is shallow, frequently near the $10 \mathrm{hPa}$. This shallow layer results from a cold surface and stable conditions. Occasionally stratocumulus form at these locations, especially over Northern Hemisphere (NH) land and Southern Hemisphere ( $\mathrm{SH}$ ) sea ice (see below), deepening the PBL while the clouds persist. Though Fig. 2 suggests the shallow PBL is the dominant regime here, the deeper regime also influences the mean value. This modification is due to strong seasonal variation, discussed below.

\section{b. Seasonal variation}

The phase and amplitude of the seasonal variation of PBL depth in the 10-yr simulation is shown in Fig. 3. For many locations large seasonal variation is associated with changes in PBL regime, which modifies the climatological depth.

The largest seasonal variation is found over the $\mathrm{NH}$ storm tracks, where the amplitude is $\geq 100 \mathrm{hPa}$, generally exceeding the mean value $(\approx 70 \mathrm{hPa})$. The maximum PBL depth occurs here during boreal autumn and winter. As cold, continental air is advected over the warm western boundary currents, the lower atmosphere becomes unstable and a deep PBL forms. The surface air reaches the LCL and low clouds form, interpreted as stratocumulus in the GCM. The resulting stratocumulus-topped boundary layer is thus a strong seasonal phenomena, existing only during the wintertime.

Throughout the SH sea ice region around the Antarctic coast, the PBL depth generally reaches its sea- 


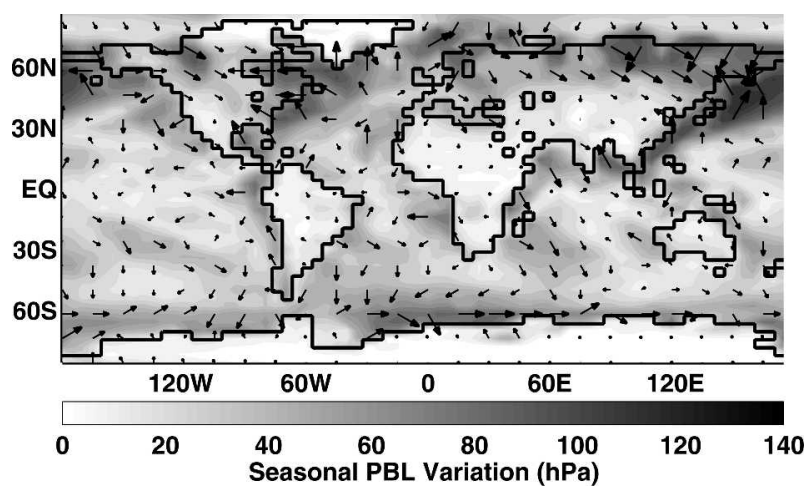

FIG. 3. Phase and amplitude of the seasonal cycle of PBL depth. The amplitude is determined at each point by taking the difference of the months with maximum and minimum mean PBL depth, and the phase is defined by the maximum. The arrows show the amplitude by length, and the phase by their orientation. Jan is straight up, and months progress clockwise. Vectors are printed only at every third grid point to increase visibility. The underlying contours are the amplitude of the seasonal cycle.

sonal maximum in early austral autumn. This corresponds with the minimum sea ice concentration and highest sea surface temperature. The seasonal variation is not as large as that of the $\mathrm{NH}$ storm tracks $(\approx 60 \mathrm{hPa})$, but it is larger compared to the mean $(\approx 25 \mathrm{hPa})$. Most of the year the sea ice region is dominated by the frozen surface cooling the surface air, inhibiting convection. A persistent SBL forms; a deeper PBL exists only during the few months without sea ice when surface fluxes produce turbulent kinetic energy.

Local maxima in seasonal variation of PBL depth associated with marine stratocumulus are also evident in Fig. 3. These signals are suggestive of the observed seasonal cycle of stratocumulus (Klein and Hartmann 1993). The agreement is most apparent in the northeast Pacific, where the maximum PBL depth (June) corresponds well with the observed maximum cloudiness [June-July-August (JJA)]. The deepest PBL over the Namibian and Peruvian stratocumulus regions also agree with the observed cloudiness maximum [September-October-November (SON)]. The similarity to observed cloudiness does not hold for the northeast Atlantic, where Klein and Hartmann (1993) show maximum low cloud during summer. The GCM has two maxima here, one during winter off northwest Africa and a second during summer near Gibraltar. The disagreement may arise because synoptic disturbances occur frequently in the region, making the seasonal signal noisier in both observations and the simulation. Similar noise is also present for the Australian stratus region, which is not analyzed by Klein and Hartmann (1993). The GCM shows a weak maximum during November.

Most land locations have relatively little seasonal variation, but across northern Asia and Canada the seasonal amplitude exceeds the mean depth by a factor of 2 or more for many grid points. There is also corresponding variation in stratocumulus incidence; the clouds develop during boreal spring and summer when ground temperature rises and destabilizes the lower atmosphere, allowing convective mixing to increase the PBL depth to the LCL. When this occurs, the PBL regime is most similar to marine stratocumulus.

In summary, marine stratocumulus regions, northern Asia and Canada, the NH storm tracks, and SH sea ice regions all exhibit variability associated with seasonal boundary layer clouds. A comparison with the seasonal cycle of simulated stratus incidence (not shown) shows that most regions with a seasonal cycle of PBL depth $\geq 70 \mathrm{hPa}$ correspond well with seasonal amplitudes of stratocumulus incidence $\geq 60 \%$. The phase also agrees; when stratocumulus are most abundant, PBL depth reaches its maximum. Stratocumulus can modify the surface energy budget, including damping diurnal variations, the focus of the next subsection.

\section{c. Diurnal variation}

Figure 4 shows the phase and amplitude of the diurnal cycle of PBL depth from one year of the simulation. The land-sea contrast is even more striking than in Fig. 2, with much of the land exhibiting large daily variations. Especially pronounced diurnal variation is seen over subtropical deserts. Generally the maximum PBL depth over land occurs around 1800 LT, near sunset. This timing is consistent with observations (Yanai and

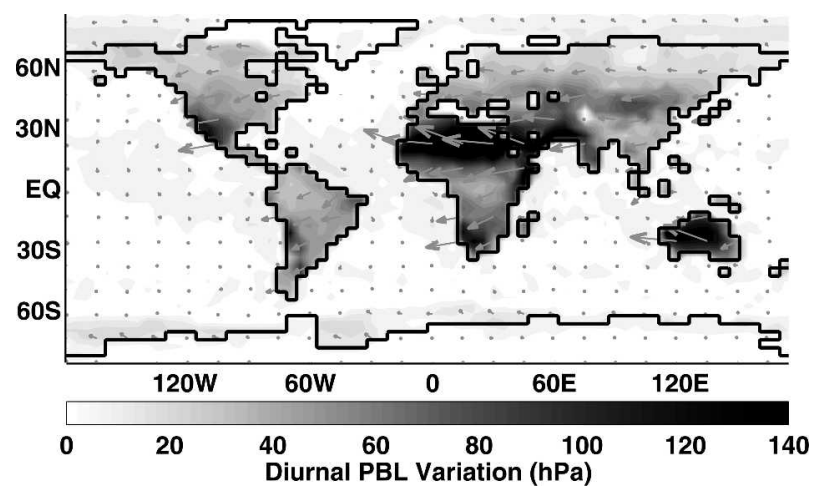

FIG. 4. Phase and amplitude of diurnal cycle of PBL depth. Description is as in Fig. 3, but the arrows represent the hour of the day in local time with midnight up and progressing clockwise such that $0600 \mathrm{LT}$ is to the right, $1200 \mathrm{LT}$ is down, and $1800 \mathrm{LT}$ is left. The upper limit on PBL depths is taken into account by including thermodynamically identical model levels as part of the PBL. This adjustment changes the magnitude of the diurnal cycle but not the phase. As in Fig. 3, only one-third of the vector field is displayed to aid visibility. 
Li 1994; Betts et al. 1996; Barr and Betts 1997; LeMone et al. 2000), though the maximum depth is underestimated by the GCM. For example, mixed layers were commonly observed to reach higher than $3 \mathrm{~km}$ during the Boreal Ecosystem-Atmosphere Study (BOREAS) (Sellers et al. 1995), while the GCM rarely predicts a maximum PBL depth greater than about $1.5 \mathrm{~km}$ for the same region of Canada.

Comparing two PBL depth time series from July (Fig. 5) illustrates the difference in PBL depth over land and ocean. The land grid point is in the Sahara $\left(26^{\circ} \mathrm{N}, 0^{\circ}\right)$, where high daytime temperatures indicate large surface buoyancy flux. This leads to the deep PBL during the afternoon. The ocean point $\left(22^{\circ} \mathrm{N}, 130^{\circ} \mathrm{W}\right)$ is in the northeast Pacific where stratocumulus are common during July. The mean of the Saharan time series $(63 \mathrm{hPa})$ is much smaller than its mean daily maximum $(177 \mathrm{hPa})$, while the marine series maintains a deeper PBL $(\approx 127 \mathrm{hPa})$ and has no diurnal cycle. While the GCM underestimates the daily maximum PBL depth over land, the depth of stratocumulus-topped PBLs seems reasonable. The GCM estimates PBL depth of around $1 \mathrm{~km}$ in the eastern Pacific (Fig. 2); observations from the second Dynamics and Chemistry of Marine Stratocumulus field study (DYCOMS-II) (Stevens et al. 2003) are around 800-900 $\mathrm{m}$, and those from the Eastern Pacific Investigation of Climate (EPIC) are closer to $1200 \mathrm{~m}$ (Bretherton et al. 2004).

Both the diurnal and seasonal variation of PBL depth ultimately result from the surface response to solar forcing. The contrast between Figs. 3 and 4 highlights the difference in the response time scales of ocean and land. Land surfaces have a smaller thermal conductivity than water, so they respond faster to solar forcing, allowing large diurnal variation in ground temperature and surface heat fluxes. The results shown in this section show that the land-sea contrast is the primary source of spatial variability in the climatological PBL depth, and that it is related to the diurnal variation over land. In the next section the land-sea contrast is examined in detail.

\section{The land-sea contrast}

To understand the impact of the diurnal cycle on mean PBL depth, a second GCM experiment was performed in which the diurnal cycle was removed. To eliminate diurnal variation, the incoming solar radiation was modified so each grid point receives the same insolation each day as in the original simulation, but uniformly distributed over $24 \mathrm{~h}$, much like the "toroidal sun" experiment of Randall et al. (1985). The resulting mean PBL depth (Fig. 6) shows a greatly diminished land-sea contrast compared to Fig. 2; there is little dif-

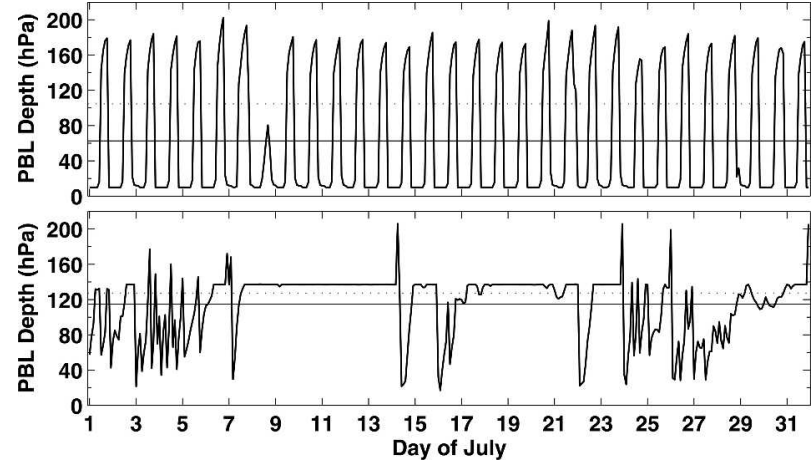

FIG. 5. Time series of PBL depth for $1 \mathrm{Jul}$ for a grid point in (top) northern Africa and (bottom) the eastern Pacific. The diurnal cycle of PBL depth is clear for the African point, but is not at all evident for the eastern Pacific. The shallow nocturnal PBL at the African point brings the mean (horizontal line at $72 \mathrm{hPa}$ ) to a fairly low value despite the deep daily maxima. The oceanic point on has a much deeper mean $(114 \mathrm{hPa})$, but less variation. The dashed lines are the Jul mean from the no-diurnal-cycle experiment at the same points.

ference over the ocean, but over land mean PBL depth changes from 29 to $57 \mathrm{hPa}$. Over deserts mean PBL depth more than doubles compared to the control simulation. The only land points where PBL depth is unaffected are high latitudes where diurnal variation is always small and Amazonia where cumulus convection was much more pervasive than in the control simulation, keeping the PBL shallow.

The diurnal behavior of the PBL over land is well known. In the simplest terms it is characterized by an extremely shallow, shear-driven SBL at night, the development of a deep convectively mixed structure in the morning and through the day, and a collapse back to a shallow layer after sunset, leaving a warm residual layer above the nocturnal PBL (cf. Stull 1988;

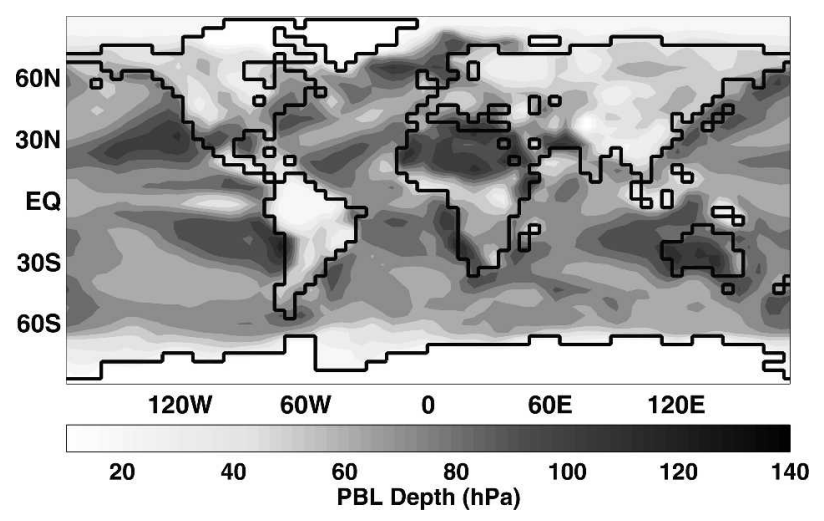

Fig. 6. Annual-mean PBL depth (hPa) from the 10-yr GCM simulation with no diurnal variation in solar insolation. The scale corresponds with that of Fig. 2. 


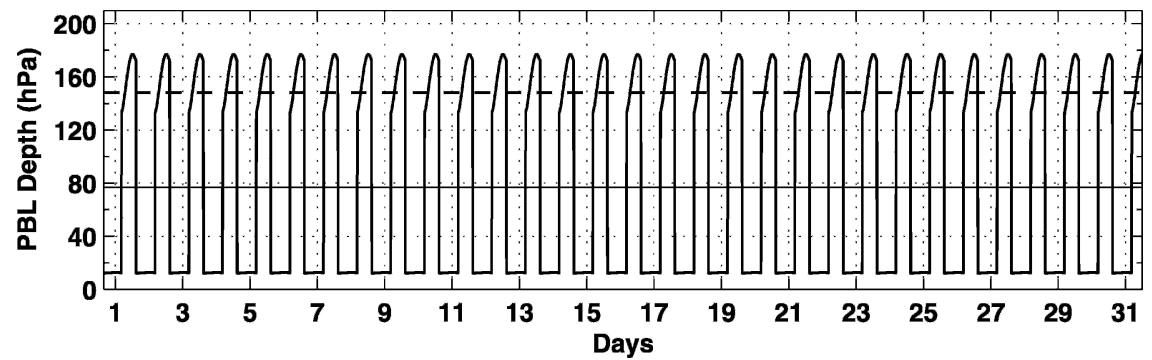

FIG. 7. Typical results from the simple CBL model. About 30 modeled days of PBL depth $(\mathrm{hPa})$ are shown as a comparison with Fig. 5. The mean of the time-varying experiment is shown as a horizontal line. The mean from the no-diurnal-cycle experiment is shown as a dashed line.

Betts et al. 1996). The nighttime PBL collapse could explain why the mean PBL depth is shallower in situations with a diurnal cycle in the forcing, assuming the mean daytime depth of the PBL is not substantially deeper at the diurnally modulated land locations than marine locations, as corroborated by Fig. 5. However, daytime surface fluxes are much greater over land. If PBL depth increased proportionally with surface forcing, daytime PBL depth would be much greater over land than ocean, and there would be little land-sea contrast when PBL depth is averaged over the day. Why does the PBL depth not respond more strongly to daytime surface fluxes? Does the development of shallow cumulus convection during daytime limit the maximum PBL depth, irrespective of the forcing, or are other processes at work?

Using a simple dry convective boundary layer model, we find the residual-layer heat budget to be a strong constraint on daily maximum PBL depth. The model is based around a surface energy budget (see appendix). The mixed layer deepens as it is warmed by the surface. When the ground cools and the heat flux becomes negative (after sunset), the mixed layer decouples from the surface and a cool, stable boundary layer forms. The residual layer is retained as a slowly cooling layer above the nighttime PBL. Such layers are often observed above the boundary layer in the morning (e.g., Betts et al. 1996). In the CBL model, the residual-layer temperature is relaxed toward a background lapse rate with a characteristic time scale, which, keeping with the simplicity of the model, is prescribed and represents radiative cooling and mixing with free atmospheric air.

Results from the CBL model are shown in Fig. 7 as a comparison to Fig. 5. The qualitative resemblance to the northern Africa GCM grid point is encouraging, suggesting the CBL model captures the processes determining PBL depth over arid regions. A no-diurnalcycle experiment was also performed with the CBL model using the mean solar forcing from the diurnally varying experiment. The mean PBL depth from both experiments are included in both figures. The basic result from the CBL model is the same as the GCM: removing diurnal variations in incoming radiation produces a much deeper PBL.

Figure 7 shows that in the diurnally varying case the peak PBL depth is only marginally deeper than the no-diurnal-cycle value, despite much larger daytime forcing. The nature of the residual layer plays a critical role in determining the daily maximum PBL depth, and consequently the mean PBL depth. This layer acts as a heat reserve for the PBL by retaining most of the thermal energy of the daytime PBL. This relationship is summarized by Fig. 8, which shows the evolution of the PBL top through the day as a function of potential temperature. The shaded area in the figure represents approximately the diurnal variation of the heat content of the system, that is, the heat lost to the free atmosphere each day. The triangle bounded by the background profile (light gray line) and the morning PBL top is the heat reserved in the residual layer during the night. The residual-layer heat budget, specifically the cooling rate (see appendix), controls the energy exchange with the free troposphere. If the residual layer does not exist (or cools instantaneously), the heat reserve disappears and both the mean and daily maximum PBL depth decrease dramatically because the PBL has to begin anew each day. If the residual layer does not cool at all, the maximum PBL depth increases while the portion of the day with a deep CBL decreases because of increased stability during the morning. This nonlinear effect of the residual layer far outweighs any other nonlinearities included in the CBL model (e.g., the nonlinear heating of the surface) in controlling the sensitivity of daytime PBL depth to surface buoyancy flux over land.

Evidently, consistent treatment of the residual-layer heat budget is crucial to the land-sea contrast seen in Fig. 2. The GCM maintains consistency by treating mix- 


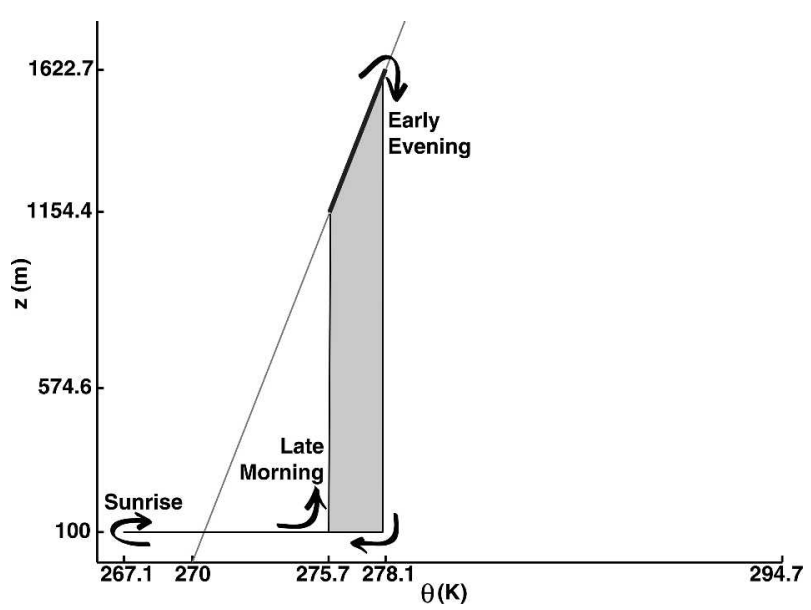

FIG. 8. Representation of the diurnal variation from the CBL model. The thin black line traces the evolution of the PBL top through the day; arrows and text give a qualitative idea of the temporal evolution. The explosive growth from $100 \mathrm{~m}$ to a deep convective layer (around $1100 \mathrm{~m}$ ) happens just after $1100 \mathrm{LT}$, and the collapse happens around 2000 LT. The light gray line is the background profile that is imposed on the system $\left(5 \mathrm{~K} \mathrm{~km}^{-1}\right)$. The thicker, darker segment at deep PBL depth shows the daily variation of the residual-layer temperature and depth. The shaded area is representative of the daily flux of heat from the PBL and residual layer to the free atmosphere, while the unshaded, bounded triangle shows the heat reserve stored by the residual layer. The range of temperatures on the horizontal axis shows the daily variation of the ground temperature. The mean PBL top height $(575 \mathrm{hPa})$ is included on the vertical axis for comparison.

ing between the PBL and the free atmosphere. That mixing implicitly incorporates a residual layer, whereas the CBL model includes it explicitly. The land-sea contrast occurs because there is a large daily exchange of heat and mass between the PBL and free atmosphere over land (Fig. 8), but over ocean variations in forcing are slower and mixing occurs primarily by entrainment. This difference between surface types suggests they should be separated before analyzing the factors controlling the climatological depth, as is done below using a PBL mass budget.

\section{The PBL mass budget}

The UCLA atmospheric GCM's mixed-layer framework uses an explicit mass budget for the PBL (Suarez et al. 1983). This eases interpretation of model output by gathering the physical processes affecting PBL depth into a few terms. Specifically, a rate equation for PBL depth can be written as

$$
\frac{D h}{D t}=E-M_{B}+W
$$

The left-hand side of (1) is the substantial derivative of the PBL depth, $h$, and on the right-hand side $E, M_{B}$, and $W$ are the turbulent entrainment rate, cumulus mass flux, and large-scale vertical velocity, respectively. Entrainment is the rate free atmospheric air is incorporated into the PBL. Cumulus mass flux removes mass from the PBL as determined by the GCM's cumulus parameterization (Arakawa and Schubert 1974). The large-scale vertical motion does not change the total PBL mass, but redistributes it horizontally.

In steady state the left-hand side of (1) vanishes and the vertical motion may be taken as constant. This allows the large-scale subsidence to be written $W=-D h$, where $D=-\partial_{z} w=\partial_{x} u+\partial_{y} v$ is the divergence at the top of the PBL. Rearranging gives a first approximation for the climatological PBL depth,

$$
h=\frac{E-M_{B}}{D} .
$$

Outside the Tropics, $M_{B}$ is usually small, and (2) reduces to $h=E / D$. When (2) is averaged over time, there are additional eddy terms (e.g., $\left.\overline{D^{\prime} M_{B}^{\prime}}, \overline{D^{\prime} E^{\prime}}\right)$ that are ignored with hope some insights can be gleaned without considering such additional complications.

The PBL mass budget, (1), and the simplified steadystate expression, (2), imply the entrainment rate is of leading-order importance in determining PBL depth. Although there is disagreement about the precise form of the relationship (Stage and Businger 1981; Lewellen and Lewellen 1998; Stevens 2002), most theories embody the idea that entrainment rate is proportional to the ratio of buoyancy flux to a stability parameter,

$$
E=\frac{\mathcal{B}}{\sigma},
$$

where $\mathcal{B}$ is the buoyancy flux, and $\sigma$ is a stability. This expression can be thought of as the total energy available to grow the PBL (since $\mathcal{B}$ is proportional to the turbulent kinetic energy) compared to the potential barrier that must be overcome to actually increase PBL depth (because the stability gives a measure of the amount of work required to maintain the PBL depth).

The buoyancy flux can be decomposed into three terms related to the heat fluxes at the PBL boundaries. The surface sensible and latent heat fluxes warm and moisten the PBL, while cooling near the cloud-top generates cool downdrafts that descend into the PBL. Both produce positive buoyancy flux. Assuming a quasisteady state, this decomposition can be written as

$$
\mathcal{B}=\alpha_{1} \mathcal{B}_{H}+\alpha_{2} \mathcal{B}_{E}+\alpha_{3} \mathcal{B}_{R}
$$

In this expression, the subscripts $\mathrm{H}, \mathrm{E}$, and $\mathrm{R}$ denote contributions from surface sensible and latent heat 
fluxes and flux divergence due to radiative cooling near cloud top, respectively. The coefficients $\alpha_{1,2,3}$ depend on the geometry of the layer (see Stevens 2002; Lewellen and Lewellen 1998).

The simulated mean buoyancy flux, $\mathcal{B}$, is shown in Fig. 9. Equations (2) and (3) suggest a relationship between $\mathcal{B}$ and PBL depth. Some similarities exist between Figs. 2 and 9, but there are important differences as well. First among these is that the land-sea contrast of Fig. 2 is not apparent in Fig. 9. From the discussion in the previous section this is not a surprise; the forcing is large, especially over deserts where the sensible heat flux is large, but diurnal effects diminish PBL depth.

Figure 10 shows the three contributions to $\mathcal{B}$. The sensible heat flux contribution, $\mathcal{B}_{H}$, is dominant over subtropical and most midlatitude land. It is also relatively large over the $\mathrm{NH}$ storm tracks, $\mathrm{SH}$ sea ice margins, and stratocumulus regions. These correspond roughly with areas where the surface skin temperature often exceeds the air temperature. There are regions where $\mathcal{B}_{H}$ is slightly negative, most notably portions of the equatorial Indian Ocean and the western Pacific warm pool. However, most tropical marine locations are overwhelmingly dominated by the latent heat flux contribution, $\mathcal{B}_{E}$. For tropical land, $\mathcal{B}_{H}$ is the dominant contribution at most locations. Outside the Tropics, the Bowen ratio increases, and $\mathcal{B}_{E}$ is smaller than the other contributions. For extratropical oceans, the buoyancy produced by cloud-top cooling, $\mathcal{B}_{R}$, is the dominant contribution. Not surprisingly, this is especially clear for the stratocumulus regions where low clouds are more persistent than other locations.

The denominator of (3) is a stability parameter, which is sometimes written as $\Delta b$, an isentropic buoy-

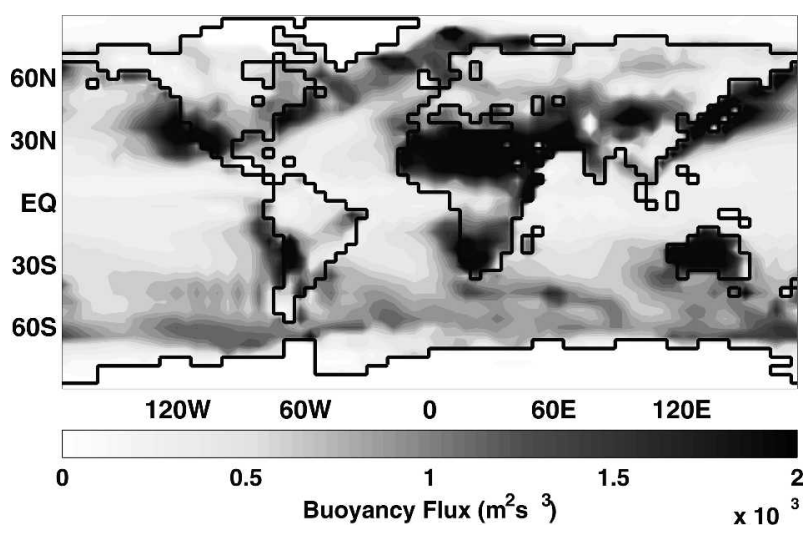

FIG. 9. The mean total buoyancy flux for the $10-y r$ simulation. Contours are spaced by $0.1 \times 10^{-3} \mathrm{~m}^{2} \mathrm{~s}^{-3}$ from 0 to $1.5 \times 10^{-3}$ $\mathrm{m}^{2} \mathrm{~s}^{-3}$. A few anomalous points do have negative $\mathcal{B}$, but are confined to polar regions and are few in number, so are plotted as zero.

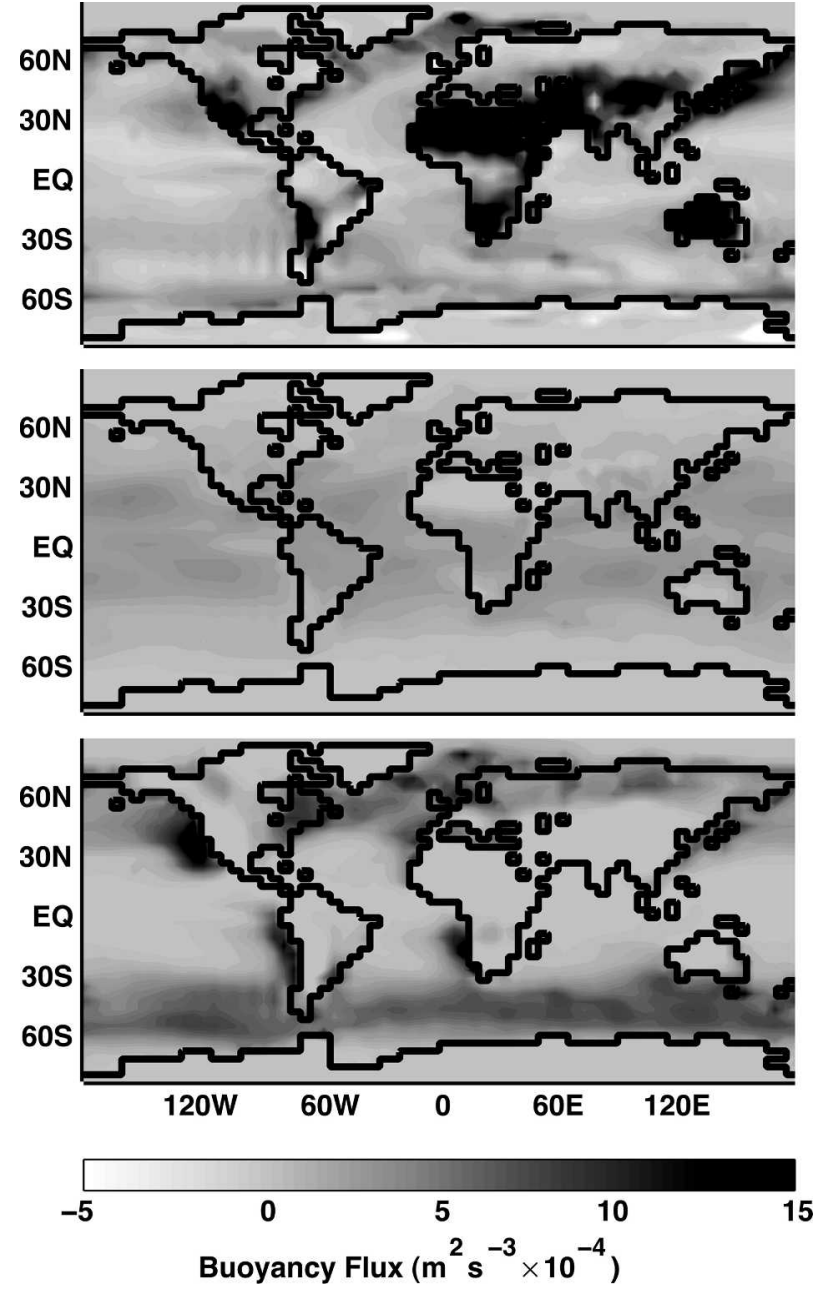

FIG. 10. (a) Contribution to the locally generated buoyancy flux due to surface sensible heat flux. Over oceans this contribution is normally negligible, while over desert regions it is important. (b) Contribution to the locally generated buoyancy flux due to surface latent heat flux. Over oceans this contribution is significant throughout the Tropics, while over higher latitudes it becomes negligible. (c) Contribution to the locally generated buoyancy flux due to longwave cooling at the top of the PBL. The stratocumulus regions are clearly defined by this field, and other stratus regions (e.g., northern Asia, circumpolar ocean) are also evident. Each of the contributions is in energetic units $\left(\mathrm{W} \mathrm{m}^{-2}\right)$. The specific heat flux and cloud-top cooling heat flux are converted to kinematic form by dividing by $c_{p} \rho$, leaving units of $\mathrm{K} \mathrm{m} \mathrm{s}^{-1}$, while the latent heat flux is converted by dividing by $L_{v} \rho$. Each plot has a contour interval of $0.1 \times 10^{-3} \mathrm{~m}^{2} \mathrm{~s}^{-3}$ from $-0.5 \times 10^{-3}$ to $1.5 \times 10^{-3}$ $\mathrm{m}^{2} \mathrm{~s}^{-3}$.

ancy difference across the top of the PBL. Here we use the lower-tropospheric stability, defined by Klein and Hartmann (1993) as the difference in potential temperature between $700 \mathrm{hPa}$ and the surface pressure, $\sigma \equiv$ $\theta_{700}-\theta_{s}$ as a surrogate for $\Delta b$. Large stability indicates either low surface temperatures (e.g., high latitudes) or elevated inversion layers (e.g., subtropics). These re- 


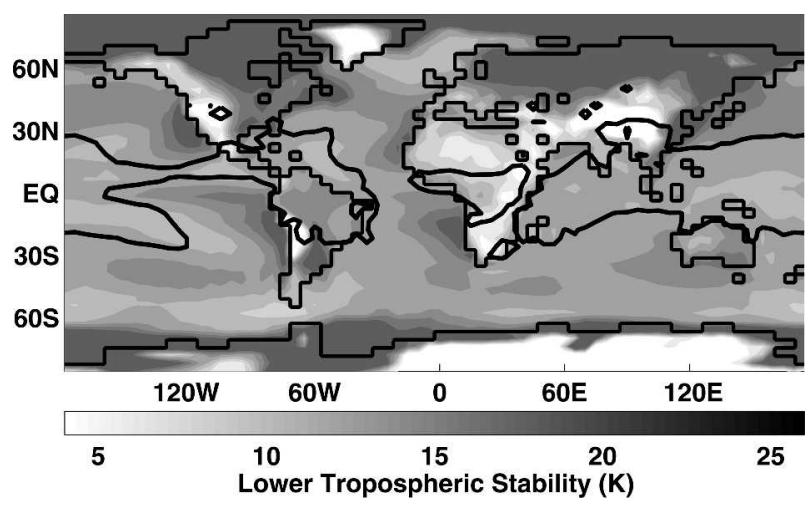

FIG. 11. Lower-tropospheric stability, $\sigma(\mathrm{K})$, shown by the contours and mean cumulus mass flux $\left(\mathrm{hPa} \mathrm{h}^{-1}\right)$ shown by the thick contour line for the 10 -yr simulation. The $\sigma$ contour spacing is $1 \mathrm{~K}$, and the $M_{B}$ contour is $0.5 \mathrm{hPa} \mathrm{h}^{-1}$.

gions are clearly evident in a map of annual-mean $\sigma$ (Fig. 11). The figure also shows some regions of extremely low stability, but most of these coincide with high surface elevation where surface pressure is not different enough from $700 \mathrm{hPa}$ to make $\sigma$ a useful quan- tity. However, northern Africa shows similarly low $\sigma$ that arises from the extreme daytime instability, and in spite of the highly stable profile prevailing during night and morning.

Oceanic regions with low stability are generally found in the Tropics, corresponding to regions of large cumulus mass flux, $M_{B}$, shown by a contour line on Fig. 11. Deep convection strongly influences the Tropics, suppressing PBL depth as in the mass budget, (1). Figure 11 illustrates the clear division between convective areas and stratiform ones in this GCM.

Comparing Fig. 2 with Figs. 9-11, it is clear there are connections between buoyancy flux, lower-tropospheric stability, cumulus mass flux, and PBL depth. These links are explored in further detail below.

\section{Geographical variation of PBL depth}

This section uses buoyancy flux $(\mathcal{B})$, cumulus mass flux $\left(M_{B}\right)$, and lower-tropospheric stability $(\sigma)$, to establish the dependence of the PBL depth and identify the mechanisms controlling it. Accordingly, Fig. 12 (a)

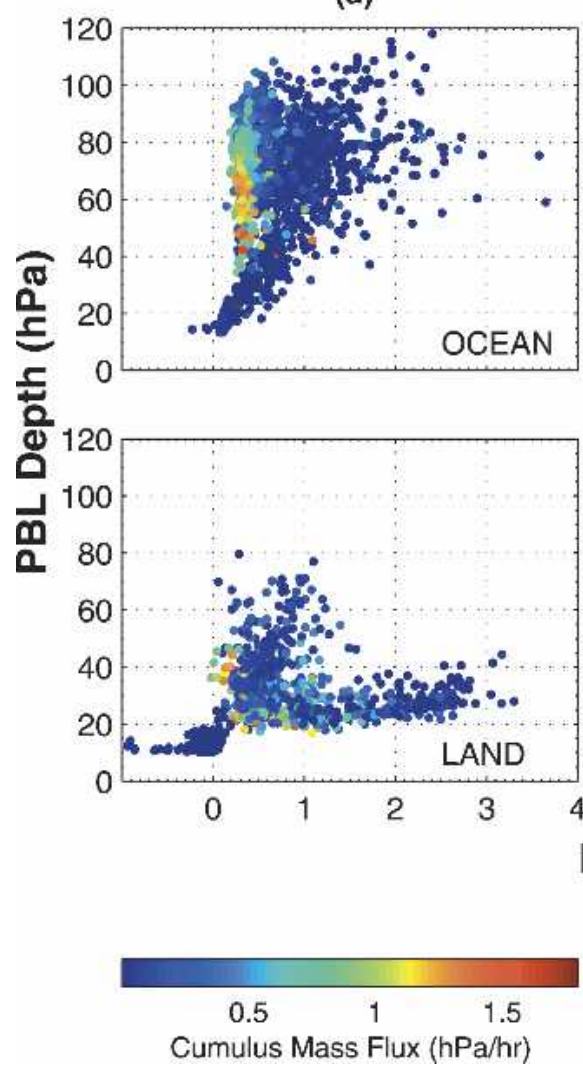

(b)
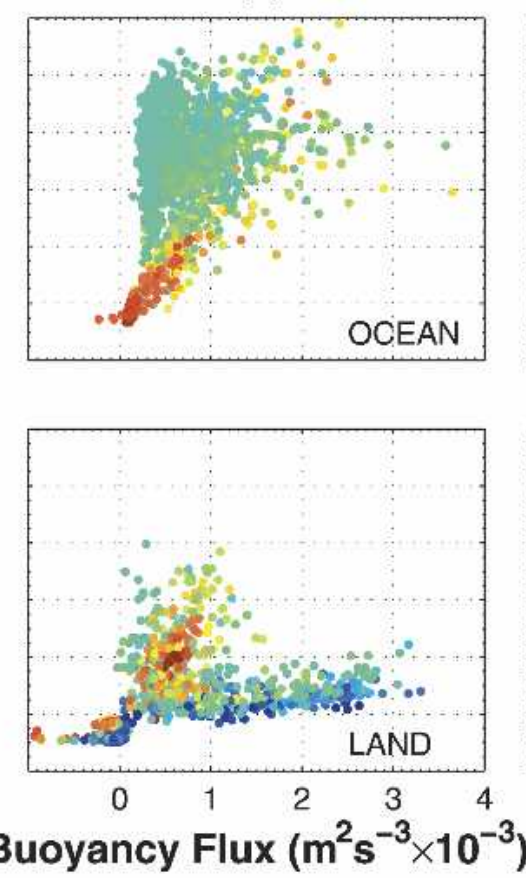

(c)
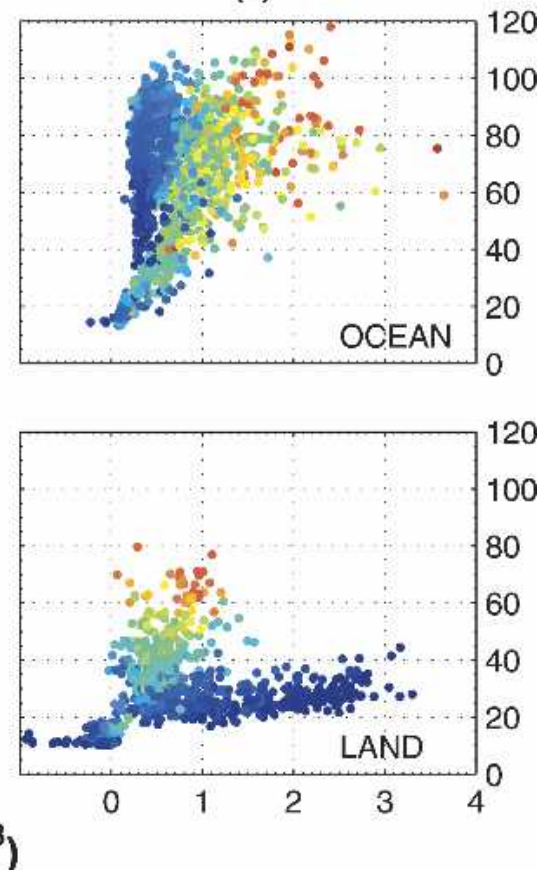

FIG. 12. Scatterplots of mean PBL depth at each grid point as a function of the mean buoyancy flux , with each column colored coded by a different variable: (a) cumulus mass flux, $M_{B}\left(\mathrm{hPa} \mathrm{h}^{-1}\right)$; (b) lower-tropospheric stability, $\sigma(\mathrm{K})$; and (c) stratus incidence (\%). The upper scatterplot of each column shows only ocean points, and the lower has only land points. The color bars are for both scatterplots. 
shows scatterplots of annual-mean PBL depth versus annual-mean $\mathcal{B}$. By coloring the distributions, several regimes from Fig. 1 become apparent, indicating the controlling mechanisms. Seasonal effects strongly influence the distributions of Fig. 12 and are discussed in section 7 .

The ocean (upper) and land (lower) distributions in Fig. 12 are quite different, as expected. The ocean points fan out from the low $\mathcal{B}$ and shallow PBL depth, $h$, with the spread in $\mathcal{B}$ increasing with PBL depth. The land points are arranged in three intersecting clusters. The upper cluster is similar to the ocean points, but reaches a shallower PBL depth. The lower one has shallow PBL depth $(h<25 \mathrm{hPa})$ and small or negative $\mathcal{B}$. The third forms along a line with small positive slope, and has the largest $\mathcal{B}$. Larger $\mathcal{B}$ generally corresponds to deeper PBL over both land and ocean, but $\mathcal{B}$ is not a perfect predictor of PBL depth; other factors are clearly involved.

The cumulus convection regime from Fig. 1 is apparent when the distributions are colored by cumulus mass flux (Fig. 12a). Over the ocean, most points with $M_{B}>$ $0.4 \mathrm{hPa} \mathrm{h}^{-1}$ have $\mathcal{B} \approx 0.4 \times 10^{-3} \mathrm{~m}^{2} \mathrm{~s}^{-3}$ and are organized vertically, with larger $M_{B}$ at shallower PBL depth. This indicates $\mathcal{B}$ contains little information about PBL depth at strongly convective locations, but it is consistent with (2), since larger $M_{B}$ represents more mass removed from the PBL. The relatively small buoyancy flux at convective locations is counterintuitive, but most buoyancy associated with deep convection occurs above cloud base (outside the PBL) through latent heat release, while $\mathcal{B}$ as defined above emphasizes surface fluxes. No region of the land distribution shows a preference for convection, suggesting $M_{B}$ contains little information about the climatological PBL depth over land.

The convective oceanic points visible in the Fig. 12a are rather less stable ( $\sigma \approx 10-13 \mathrm{~K})$, but are not distinguishable as a separate regime in Fig. 12b. Highly stable points $(\sigma>22 K)$, however, correspond to the lowest PBL depths for both ocean and land. Such large $\sigma$ represents the stable surface conditions over near-freezing SST or sea ice for oceanic points and snow- and icecovered land points. These shallow boundary layers are the SBL regime in Fig. 1 and correspond to low entrainment rates by (3). Some land points with small $\mathcal{B}$ and shallow PBL depth appear less stable (low $\sigma$ ); these are high-elevation locations-for example, Antarctica and the Tibetan Plateau-where low surface pressure makes $\sigma$ a poor representation of stability (see Fig. 11).

Many oceanic points are characterized by moderate stability $(\sigma \approx 15-20 \mathrm{~K})$ and moderate to high $\mathcal{B}(>1 \times$
TABLE 2. A summary of the regimes in Fig. 12, along with some general characteristics of each. For each $\mathcal{B}, \sigma$, and PBL depth, $h$, the regimes are described by the relative values generally associated with them. Cumulus-convection-dominated boundary layers show a range of PBL depths, depending on the value of $M_{B}$.

\begin{tabular}{llll}
\hline \hline Regime & \multicolumn{1}{c}{$\mathcal{B}$} & \multicolumn{1}{c}{$\sigma$} & \multicolumn{1}{c}{$h$} \\
\hline SBL & Low & High & Low \\
STBL & Mid/high & Mid & High \\
CBL & High & Low & Low* \\
Cumulus & Low & Low & Low/mid \\
\hline
\end{tabular}

* Diurnal effects keep the mean value low.

$10^{-3} \mathrm{~m}^{2} \mathrm{~s}^{-3}$ ), making up most of the deep PBL points. The upper cluster of the land distribution has similar characteristics, but with more modest PBL depth and $\mathcal{B}$. Figure $12 \mathrm{c}$ indicates that these are stratocumulustopped boundary layers. Over the ocean, this regime is found over eastern subtropical oceans and storm tracks (see section 3). Stratocumulus over land are mostly confined to northern Asia. The deep PBL accompanying stratocumulus develops because of high entrainment rates as in (3).

The linear feature in the land distribution extending to large $\mathcal{B}$ has modest $\sigma$ but shallow PBL depth. The third panel shows these points are clear, with almost no stratus incidence. This combination of low $\sigma$ and large $\mathcal{B}$ would indicate large entrainment rate by (3), suggesting a deep PBL in the absence of cumulus convection. These points are deserts where diurnal effects keep PBL depth low (see section 4), and so represent a dry CBL.

Table 2 summarizes the general characteristics of the PBL regimes discussed in this section. Although many locations are unmistakably dominated by these regimes, transitions between regimes are blurred. Several reasons contribute to this blending of regimes. One is that there are many locations where no single regime dominates. For example, much of the subtropical oceans have substantial buoyancy fluxes and are not strongly stratified, but have a low incidence of both cumulus convection and stratocumulus. Consequently these areas have a relatively deep PBL on average and do not fit easily into the three oceanic regimes described in this section. Another reason for the blending is seasonal shifts in PBL regime, which average to more central values in Fig. 12; these seasonal effects are discussed further below.

\section{Seasonal effects}

Seasonal variation in PBL depth (Fig. 3) is important for regional climate and can affect global climate, for 

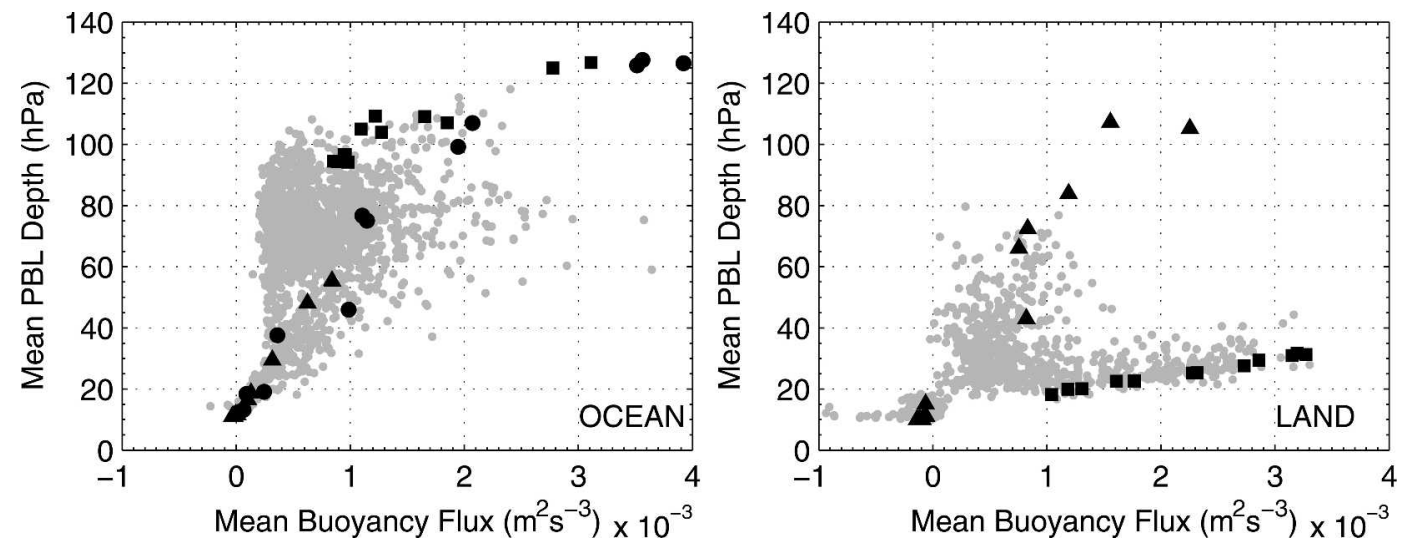

FIG. 13. Seasonal behavior for five grid points. The scatterplots show the same distributions as Fig. 12 in gray. Overlaid are monthly values for three ocean and two land points. The ocean points are NE Pacific stratocumulus (squares), NW Pacific storm track (circles), and SH sea ice (triangles). The land points are from northern Africa (squares) and northern Asia (triangles).

example, by influencing seasonal deep convection or low-level cloudiness. This section examines seasonal variations in PBL depth using the concepts from above.

In Fig. 13, monthly values of $\mathcal{B}$ and PBL depth for five grid points are plotted on top of the distributions from Fig. 12. These points were mainly chosen to be representative of regional-scale PBL behavior and to sample regions of large seasonal amplitude (see Fig. 3). The SH sea ice point (triangles) and the NH storm track point (circles) both have large seasonal variation, ranging from the shallow SBL regime to the deep stratocumulus regime. The marine stratocumulus point used in Fig. 5 is also plotted (squares). Though variation of PBL depth is small here, a large seasonal range of $\mathcal{B}$ occurs at this grid point. The northern Africa point from Fig. 5 (squares) represents the $\mathrm{CBL}$ regime, while a northern Asia point (triangles) shows the stratocumulus and SBL regimes over land and the seasonal transition between them.

Figure 13 shows the characteristics described by Table 2 can be used to understand both the geographical distribution of annual-mean PBL depth and seasonal PBL depth variation at particular grid points. Regions of persistent stratocumulus cloud cover tend to be described by large $\mathcal{B}$ and deep PBL over both land and ocean. Dry land regions also have large $\mathcal{B}$, but are restricted in PBL depth because of diurnal effects. Stable boundary layers have shallow PBL depth and small $\mathcal{B}$.

The figure also helps explain the mean distributions. Stratocumulus over land is strongly seasonal and is mostly restricted to high-latitude, $\mathrm{NH}$ land during the summer. This is consistent with the seasonal amplitude in Fig. 3 and explains why the annual-mean $\mathcal{B}$ and PBL depth for these points is smaller than marine stratocumulus on average. The NH storm tracks also display a seasonal regime shift, changing from a shallow SBL in the summer to a deep, cloud-topped PBL during the winter. Not shown in Fig. 13 are compensating effects among buoyancy fluxes, stability, and cumulus convection. For example, the marine stratocumulus location shows large seasonal variation in $\mathcal{B}$ but no proportional change in PBL depth. Larger $\mathcal{B}$ during summer is offset by larger $\sigma$, which varies seasonally here with the strength and location of the subtropical high and ITCZ.

Seasonal variation of PBL depth on regional scales may be influenced by peculiarities of the GCM. The stratocumulus-topped boundary layer depth over the NH storm tracks during winter may be somewhat exaggerated, for example, because the criterion for the CTEI parameterization is not met. The lack of CTEI in these regions allows a homogeneous stratocumulus deck to form instead of the open cellular convection that is observed. The direct consequence of overpredicted low-level cloudiness is that PBL depth will be deep during winter (Fig. 3), creating an exaggerated seasonal variation. The same effect may also influence the stratocumulus over land and SH sea ice.

\section{Evaluating the mass budget framework}

To assess the statistical significance of the relationships inferred from Fig. 12, a regression analysis is used. PBL depth is taken as the dependent variable and up to five predictor variables are used. The predictor variables were chosen from the components of the buoyancy flux, lower-tropospheric stability, and cumulus mass flux. Divergence was found to be a poor predictor variable, probably because it is a "noisy" field. Though many regressions were calculated, this discussion is limited to one and five variables, as these reveal the most 
important physical insights. Because of the difference in PBL behavior over land and ocean, they are discussed separately.

Correlations between predictor variables and PBL depth showed differences between the land and ocean points. Lower-tropospheric stability, $\sigma$, is the best predictor over the ocean, while buoyancy flux due to cloud-top cooling, $\mathcal{B}_{R}$, does the best over land. Lowertropospheric stability is anticorrelated with PBL depth and accounts for $65 \%$ of the variability for the ocean points while $\mathcal{B}_{R}$ accounts for $66 \%$ of the variability in PBL depth over land.

For both land and ocean, the best predictor variables ( $\mathcal{B}_{R}$ and $\sigma$, respectively) are variables that can discriminate between clear and cloudy boundary layers. The fact that the best predictor is different between land and ocean gives some sense that there is a fundamental difference arising from the land-sea contrast discussed in section 4. Lower-tropospheric stability explains much of the oceanic variability by differentiating between the less stable low latitudes and the highly stable high latitudes, and it contains information about regional-scale variability associated with cloud-topped PBL regimes. Over land, $\mathcal{B}_{R}$ is the best predictor because it discriminates clear and cloudy boundary layers. It is a better predictor than $\sigma$ over land because diurnal and topographic effects erode the effectiveness of $\sigma$ in capturing PBL depth variability over land.

Using all five variables $\left(\mathcal{B}_{H, E, R}, \sigma\right.$, and $\left.M_{B}\right)$ accounts for $83 \%$ of PBL depth variability over land, and almost $91 \%$ of the variability over ocean. The resulting estimates for PBL depth are given by

$$
\begin{aligned}
\widehat{h_{o}=} & 60.27-6005 \mathcal{B}_{H}+1.424 \times 10^{5} \mathcal{B}_{E}+32130 \mathcal{B}_{R} \\
& -1.830 \sigma-12.58 M_{B}, \\
\widehat{h_{l}=} & 12.72+4434 \mathcal{B}_{H}+43990 \mathcal{B}_{E}+56003 \mathcal{B}_{R} \\
& +0.0425 \sigma-2.207 M_{B} .
\end{aligned}
$$

The much larger regression constant for ocean (60 versus 12) suggests the larger oceanic mean PBL depth. In both expressions, the $\mathcal{B}_{H}$ coefficient is much smaller than the other buoyancy contributions, showing the relative insignificance of sensible heat flux anomalies for mean PBL depth. In both expressions the other buoyancy flux coefficients are positive, with $\mathcal{B}_{E}$ especially dominant over ocean and $\mathcal{B}_{R}$ largest over land. Ocean points are most sensitive to $\mathcal{B}_{E}$ because changes in latent heat flux are most likely to correspond with a change in PBL regime, while over land $\mathcal{B}_{R}$ more successfully indicates changes between regimes. The $\sigma$ coefficient is opposite signed for ocean and land. Ocean locations have a strong anticorrelation between PBL depth and $\sigma$, as discussed above, while $\sigma$ is nearly negligible over land. Cumulus mass flux reduces PBL depth everywhere, but is more predictive for ocean, as inferred from Fig. 12. These results show the mass budget framework is appropriate for understanding the mean behavior of the PBL.

\section{Summary and conclusions}

This paper seeks an understanding of the large-scale spatial structure of climatological PBL depth, including seasonal and diurnal variations. The analysis uses the UCLA atmospheric GCM, a simple convective boundary layer model, and the PBL mass budget to show the PBL is organized into a few regimes and the depth is controlled largely by a few parameters. The most common regimes are stratocumulus-topped boundary layers, dry convective boundary layers, stable boundary layers, and shallow boundary layers under the influence of deep convection. Some general characteristics of these regimes are listed in Table 2 and are represented schematically in Fig. 1. The global perspective presented here anticipates global PBL datasets providing sufficient information for a similar analysis, which could be useful in understanding the PBL and its role in climate as well as comparison with climate models.

Great effort was devoted to parameterizing the PBL in the UCLA atmospheric GCM, with special care given to the treatment of boundary layer clouds. The representation of stable boundary layers, however, suffers somewhat under the assumptions used. Relying on a CTEI assumption may also have an impact on mean PBL depth by overpredicting seasonal cloud cover over land and storm tracks. Despite these deficiencies, the mixed-layer framework compares favorably against other PBL schemes (Ayotte et al. 1996).

Figure 2 shows a strong land-sea contrast in annualmean PBL depth, with much shallower PBL over land. A GCM simulation excluding diurnal variation in sunshine showed much less difference between land and ocean (Fig. 6). A CBL model also shows an increase in mean PBL depth without the diurnal cycle. In this CBL model the nightly PBL collapse reduces mean PBL depth and creates a residual layer above the PBL. The residual layer acts as a heat reserve for the PBL, allowing its heat budget to control both daily maximum PBL depth and the fraction of the day with a deep PBL. These effects are strong over land, where surface thermal conductivity is small, but the ocean feels much less diurnal variation. This leads to the land-sea contrast apparent in Fig. 2. The diurnal variation of PBL depth has important implications for surface-atmosphere exchange (see also Denning et al. 1996), and its representation may be necessary for many applications. 
The PBL mass budget, (1), decomposes the processes affecting PBL depth, and the steady-state solution, (2), gives an approximate expression for PBL depth. Locally generated buoyancy fluxes and lower-tropospheric stability account for most of the spatial variability in annual-mean PBL depth. These are related to the entrainment rate by (3), and PBL depth scales as the entrainment rate. Cumulus mass flux can also play an important role in PBL depth over the tropical ocean. Figure 12 captures much of the large-scale organization of PBL depth, clearly showing the most prevalent PBL regimes and the difference between land and ocean. Regression analysis shows the mass budget approach successfully accounts for most PBL depth variability on large scales, and indicates the relative importance of the mass budget terms. The majority of the variability is accounted for by only a few predictor variables. Such an estimation may be useful in the development of simplified climate models in which detailed PBL schemes are an impediment.

Acknowledgments. This work was supported by NSF Grants ATM-0135136 and ATM-9985413.

\section{APPENDIX}

\section{A Simple CBL Model}

The formulation of the simple CBL model is similar to Tennekes (1973) and Carson (1973). To start, an environmental temperature profile, $\theta(z)=\theta_{\text {ref }}+\Gamma h$, is prescribed, where $\theta$ is potential temperature, $\theta_{\text {ref }}$ a reference temperature, $\Gamma$ a stability, and $h$ the PBL depth. This is solved for $h$ once $\theta(z)$ is determined. When a well-mixed assumption is included, the vertical dependence vanishes. The PBL's potential temperature is determined by surface heat fluxes. To obtain the heat flux, a surface energy balance is used to establish the ground temperature, $T_{g}$,

$$
c_{\mathrm{pg}} \frac{d T_{g}}{d t}=S-\sigma T_{g}^{4}-F,
$$

where $c_{\mathrm{pg}}$ is the surface isobaric specific heat, $S$ is incoming radiative flux, $\sigma T_{g}^{4}$ is outgoing blackbody radiation, and $F$ is surface heat flux.

For experiments with a diurnal cycle, the incoming radiation is a clipped sine wave,

$$
S=\left\{\begin{array}{ll}
S_{\odot} \sin \left(\frac{2 \pi t}{\Omega_{\oplus}}\right) & \text { if } \sin \left(\frac{2 \pi t}{\Omega_{\oplus}}\right)>0 \\
0 & \text { if } \sin \left(\frac{2 \pi t}{\Omega_{\oplus}}\right) \leq 0
\end{array},\right.
$$

where $S_{\odot}$ is the solar flux and $\Omega_{\oplus}\left(=86400 \mathrm{~s}^{-1}\right)$ is the rotation frequency of earth. When the diurnal cycle is removed, $S$ is set to its mean from the time-varying experiment.

Sensible heat flux is determined from a bulk aerodynamic formula, $F=c_{\mathrm{pd}} \rho C_{D}\|\mathbf{V}\|\left(T_{g}-\theta\right)$, where $C_{D}$ (=0.0011) and $\|\mathbf{V}\|$ is a prescribed mean wind speed. The mixed-layer potential temperature is used since it is identical to the surface air temperature by construction.

The evolution of the potential temperature is taken as the change in vertical heat flux $\left[\partial_{t} \theta=-\partial_{z}\left(\overline{\bar{w}^{\prime} \theta^{\prime}}\right)\right]$. Integrating across the PBL, and assuming the heat flux at the CBL top is $20 \%$ of the surface value $\left[-\left(\overline{w^{\prime} \theta^{\prime}}\right)_{h}=\right.$ $\left.0.2\left(\overline{w^{\prime} \theta^{\prime}}\right)_{0}\right]$ gives an expression for potential temperature, $\partial_{t} \theta=1.2\left(\overline{w^{\prime} \theta^{\prime}}\right)_{0} h^{-1}$.

The surface heat flux is transformed between kinematic and energetic units by $c_{\mathrm{pd}} \rho\left(\overline{w^{\prime} \theta^{\prime}}\right)_{0}=F$. This gives an equation for the potential temperature in terms of $F$ and $h\left[\partial_{t} \theta=1.2 F\left(c_{\mathrm{pd}} \rho h\right)^{-1}\right]$ and closes this model.

To model the diurnal variation in PBL height, it is necessary to allow a rapid collapse of the PBL. The collapse is due a surface inversion forming when the ground cools, decoupling the surface fluxes from the daytime mixed layer. In keeping with the simplicity of the current framework, a switching rule determines the collapse of the PBL,

$$
h=\left(\frac{\theta_{\mathrm{ML}}-\theta_{\text {ref }}}{\Gamma}\right) \mathcal{H}(F)+h_{\text {min }} \mathcal{H}(-F),
$$

where $\mathcal{H}$ denotes the Heaviside function, and $h_{\text {min }}$ is a minimum PBL height representing mechanically driven turbulence (usually set to $100 \mathrm{~m}$ ). To avoid instantaneous mixing of residual-layer air, and maintain a consistent heat budget, the residual layer is explicitly included. This layer is considered well mixed in $\theta$, whose initial value is determined by the deep daytime PBL. A relaxation parameter, $\tau$, represents the time it takes for the residual layer to cool to the free tropospheric lapse rate,

$$
\frac{d \theta_{r}}{d t}=\left(\frac{\theta_{\mathrm{ML}}-\theta_{\mathrm{ref}}}{\tau}\right) .
$$

In this case, $\theta_{\mathrm{ML}}$ is the larger of the mixed-layer or residual-layer potential temperature.

Without (A3) the model cannot reproduce the daily cycle of PBL depth (Fig. 5), but it complicates the heat budget. Equation (A4) is a parameterization of diabatic processes that fits with our simple approach to the problem, and it successfully balances the heat budget.

The choice of $\tau$ accounts for radiative cooling and mixing in the residual layer, so depends on factors not taken into account by this CBL model. A test of the sensitivity of the CBL model to this time scale is shown in Fig. A1. As $\tau$ increases, the mean and maximum daily 


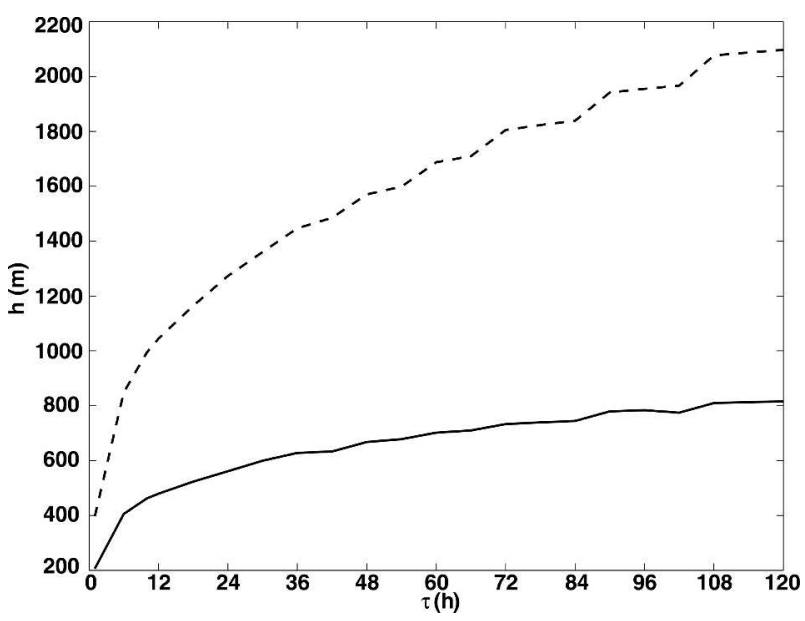

FIG. A1. Sensitivity of mean and maximum PBL height (m) to residual-layer relaxation time scale, $\tau(\mathrm{h})$. The solid line is the mean PBL top height from the CBL model, and the dashed line is the peak height. Experiments were run with $\tau$ equal to 1, 6, 10, and multiples of 6 up to $120 \mathrm{~h}$.

PBL depth increase parabolically as less heat acquired by the residual layer from the PBL is lost during the night. Daily maximum PBL depth is somewhat more sensitive to changes in the relaxation time scale than mean PBL depth. This follows the reasoning given in section 4.

\section{REFERENCES}

Albrecht, B. A., C. S. Bretherton, D. Johnson, W. S. Schubert, and A. S. Frisch, 1995: The Atlantic stratocumulus transition experiment-ASTEX. Bull. Amer. Meteor. Soc., 76, 889-904.

Arakawa, A., and W. H. Schubert, 1974: Interaction of a cumulus cloud ensemble with the large-scale environment, Part I. $J$. Atmos. Sci., 31, 674-701.

Avissar, R., and C. Nobre, 2002: Preface to special issue on the Large-Scale Biosphere-Atmosphere Experiment in Amazonia (LBA). J. Geophys. Res., 107, 8034, doi:10.1029/2002JD002507.

Ayotte, K. W., and Coauthors, 1996: An evaluation of neutral and convective planetary boundary-layer parameterizations relative to large eddy simulations. Bound.-Layer Meteor., 79, $131-175$.

Barr, A. G., and A. K. Betts, 1997: Radiosonde boundary layer budgets above a boreal forest. J. Geophys. Res., 102 (D24), 29 205-29 212.

Betts, A. K., J. H. Ball, A. C. M. Beljaars, M. J. Miller, and P. A. Viterbo, 1996: The land surface-atmosphere interaction: A review based on observational and global modeling perspectives. J. Geophys. Res., 101 (D3), 7209-7225.

Bretherton, C. S., and Coauthors, 2004: The EPIC 2001 stratocumulus study. Bull. Amer. Meteor. Soc., 85, 967-977

Carson, D., 1973: The development of a dry inversion-capped convectively unstable boundary layer. Quart. J. Roy. Meteor. Soc., 99, 450-467.

Deardorff, J. W., 1972: Parameterization of the planetary boundary layer for use in general circulation models. Mon. Wea. Rev., 100, 93-106.

_ 1980: Cloud top entrainment instability. J. Atmos. Sci., 37, 131-147.
Denning, A. S., D. A. Randall, G. J. Collatz, and P. J. Sellers, 1996: Simulations of terrestrial carbon metabolism and atmospheric $\mathrm{CO}_{2}$ in a general circulation model: Part 2: Simulated $\mathrm{CO}_{2}$ concentrations. Tellus, 48B, 543-567.

Garratt, J., L. Rotstayn, and P. Krummel, 2002: The atmospheric boundary layer in the CSIRO global climate model: Simulations versus observations. Climate Dyn., 19, 397-415.

Klein, S. A., and D. L. Hartmann, 1993: The seasonal cycle of low stratiform clouds. J. Climate, 6, 1587-1606.

LeMone, M. A., and Coauthors, 2000: Land-atmosphere interaction research, early results, and opportunities in the Walnut River Watershed in southeast Kansas: CASES and ABLE. Bull. Amer. Meteor. Soc., 81, 757-779.

Lenschow, D. H., and Coauthors, 1988: Dynamics and chemistry of marine stratocumulus (DYCOMS) experiment. Bull. Amer. Meteor. Soc., 69, 1058-1067.

Lewellen, D., and W. Lewellen, 1998: Large-eddy boundary layer entrainment. J. Atmos. Sci., 55, 2645-2665.

Li, J.-L. F., and A. Arakawa, 1999: Improved simulation of PBL moist processes with the UCLA GCM. Preprints, Seventh Conf. on Climate Variation, Long Beach, CA, Amer. Meteor. Soc., 35-40.

_, M. Köhler, J. D. Farrara, and C. Mechoso, 2002: The impact of stratocumulus cloud radiative properties on surface heat fluxes simulated with a general circulation model. Mon. Wea. Rev., 130, 1433-1441.

Lilly, D. K., 1968: Models of cloud topped mixed layers under a strong inversion. Quart. J. Roy. Meteor. Soc., 94, 292-309.

Lock, A., A. Brown, M. Bush, G. Martin, and R. Smith, 2000: A new boundary layer mixing scheme. Part I: Scheme description and single-column model tests. Mon. Wea. Rev., 128, 3187-3199.

Martin, G., M. Bush, A. Brown, A. Lock, and R. Smith, 2000: A new boundary layer mixing scheme. Part II: Tests in climate and mesoscale models. Mon. Wea. Rev., 128, 3200-3217.

McCormick, M. P., and Coauthors, 1993: Scientific investigations planned for the Lidar In-space Technology Experiment (LITE). Bull. Amer. Meteor. Soc., 74, 205-214.

Mechoso, C. R., J.-Y. Yu, and A. Arakawa, 2000: A coupled GCM pilgrimage: From climate catastrophe to ENSO simulations. General Circulation Model Development: Past, Present, and Future, D. A. Randall, Ed., Academic Press, 539-575.

Moeng, C.-H., and B. Stevens, 2000: Marine stratocumulus and its representation in GCMs. General Circulation Model Development: Past, Present, and Future, D. A. Randall, Ed., Academic Press, 577-604.

Neiburger, M., D. S. Johnson, and C.-W. Chien, 1961: Studies of the structure of the atmosphere over the eastern Pacific ocean in summer. University of California Tech. Rep., 94 pp.

Randall, D. A., 1980: Entrainment into a stratocumulus layer with distributed radiative cooling. J. Atmos. Sci., 37, 148-159.

, J. A. Abeles, and T. G. Corsetti, 1985: Seasonal simulations of the planetary boundary layer and boundary-layer stratocumulus clouds with a general circulation model. J. Atmos. Sci., 42, 641-676.

— Q. Shao, and M. Branson, 1998: Representation of clear and cloudy boundary layers in climate models. Clear and Cloudy Boundary Layers, A. A. M. Holtslag and P. G. Duynkerke, Eds., Royal Netherlands Academy of Arts and Sciences, 305322. 
Sellers, P. J., F. G. Hall, G. Asrar, D. E. Strebel, and R. E. Murphy, 1992: An overview of the First ISLSCP Field Experiment. J. Geophys. Res., 97 (D17), 18 345-18 372.

- and Coauthors, 1995: The Boreal Ecosystem-Atmosphere Study (BOREAS): An overview and early results from the 1994 field year. Bull. Amer. Meteor. Soc., 76, 1549-1577.

Stage, S. A., and J. A. Businger, 1981: A model for entrainment into a cloud-topped marine boundary layer. Part I: Model description and application to a cold-air outbreak episode. $J$. Atmos. Sci., 38, 2213-2229.

Stevens, B., 2002: Entrainment in stratocumulus-topped mixed layers. Quart. J. Roy. Meteor. Soc., 128, 2663-2690.

— , and Coauthors, 2003: Dynamics and chemistry of marine stratocumulus-DYCOMS-II. Bull. Amer. Meteor. Soc., 84, 579-593.

Stull, R. B., 1988: Introduction to Boundary Layer Meteorology. Kluwer Academic, 666 pp.
Suarez, M., A. Arakawa, and D. Randall, 1983: The parameterization of the planetary boundary layer in the UCLA general circulation model: Formulation and results. Mon. Wea. Rev., 111, 2224-2243.

Tennekes, H., 1973: A model for the dynamics of the inversion above a convective boundary layer. J. Atmos. Sci., 30, 558567.

Uttal, T., and Coauthors, 2002: Surface heat budget of the Arctic Ocean. Bull. Amer. Meteor. Soc., 83, 255-276.

Webster, P. J., and R. Lukas, 1992: TOGA COARE: The Coupled Ocean-Atmosphere Response Experiment. Bull. Amer. Meteor. Soc., 73, 1377-1416.

Winker, D. H., R. H. Couch, and M. P. McCormick, 1996: An overview of LITE: NASA's Lidar In-space Technology Experiment. Proc. IEEE, 84 (2), 1-17.

Yanai, M., and C. Li, 1994: Mechanism of heating and the boundary layer over the Tibetan Plateau. Mon. Wea. Rev., 122, 305-323. 